LBNL-51917

\title{
Multiproject Baselines for Evaluation of Electric Power Projects
}

\author{
Jayant Sathaye, Scott Murtishaw, and Lynn Price \\ Lawrence Berkeley National Laboratory, Berkeley, CA \\ Maurice Lefranc \\ US Environmental Protection Agency, Washington DC \\ Joyashree Roy \\ Jadavpur University, Calcutta, India \\ Harald Winkler, Randall Spalding-Fecher \\ University of Cape Town, Cape Town, South Africa
}

\begin{abstract}
Calculating greenhouse gas emissions reductions from climate change mitigation projects requires construction of a baseline that sets emissions levels that would have occurred without the project. This paper describes a standardized multiproject methodology for setting baselines for electric power projects, using a reference case emissions rate $(\mathrm{kg} \mathrm{C} / \mathrm{kWh})$. Standardized multiproject emissions rates offer the possibility to significantly reduce the transaction costs of projects. The most challenging aspect of setting multiproject emissions rates is determining the vintage and types of plants to include in the baseline and the stringency of the emissions rates to be considered, in order to balance the desire to encourage no- or low-carbon projects while maintaining environmental integrity. The criteria for selecting power plants to include in the baseline depend on characteristics of both the project and the electricity grid it serves. Two case studies illustrate the application of these concepts to the electric power grids in eastern India and South Africa. We use hypothetical, but realistic, climate change projects in each country to illustrate the use of the multiproject methodology, and note the further research required to fully understand the implications of the various choices in constructing and using these baselines.
\end{abstract}

Keywords: baselines, multiproject, electric power, greenhouse gas emissions, climate change projects, India, South Africa, benchmark, performance standard, additionality, Clean Development Mechanism 


\section{Introduction}

Estimating greenhouse gas (GHG) emissions reductions of climate change mitigation projects ${ }^{1}$ is a several-step process. These steps include (1) determination of additionality or eligibility of a project, (2) construction of a baseline that approximates emissions levels that would have occurred without the project, (3) adjustment of the baseline to account for free riders, (4) calculation of project emissions, (5) adjustment of these calculations for potential leakage, and finally, (6) estimation of GHG reductions relative to the baseline. Additionally, the estimated baseline may be subject to periodic adjustment to reflect changes in the business-as-usual (BAU) conditions.

In order to receive credits for reducing GHG emissions within a given carbon trading scheme, a project will be subjected to additionality or eligibility tests (step 1) before being accepted as a qualified project. These tests are designed to ensure that a proposed project will result in real GHG emissions reductions that would not have occurred in the absence of the project. This paper focuses on the estimation of BAU emissions and the reductions from projects for which additionality has already been determined, although we discuss how the performance benchmarks ${ }^{2}$ created by our method could be useful for establishing environmental additionality. ${ }^{3}$ We do not treat the complex issues surrounding free-ridership and leakage (steps 3 and 5)(see Chomitz 2002, Liu \& Rogers 2000).

The determination of a baseline (step 2) requires the estimation of current and future activity (electricity generated or saved for an electricity project) and emissions rates $(\mathrm{kg} \mathrm{C} / \mathrm{kWh})$ under the BAU scenario. ${ }^{4}$ Multiplying the activity and emissions rate yields an emissions baseline ( $\mathrm{kg}$ C). Similarly, a project's emissions can be estimated as a function of its output and emissions rate (step 4). The estimated reduction due to the project (step 6) is simply the difference between the project's emissions and the emissions that would have occurred to supply the same amount of electricity at the BAU emissions rate.

Earlier authors have noted that climate change mitigation project baselines can be projectspecific, multiproject, or a hybrid of the two (Ellis and Bosi, 1999). Project-specific baselines are determined on a project-by-project basis using specific measurements or assumptions. Multiproject baselines (MPBs) use existing or estimated emissions levels from a defined set of actual or planned near-future plants to derive a standard baseline to which several projects can be compared. Setting a project-specific baseline also requires collection of data and information upon which to base estimates of baseline emissions rates. The decision-making that goes into

\footnotetext{
${ }^{1}$ Unless noted otherwise, the word "project" as used in this paper refers to a climate change mitigation project.

${ }^{2}$ While a baseline is a projected level of emissions, a benchmark refers to a rate of emissions per unit of output that serves as a performance standard to which projects are compared.

${ }^{3}$ In addition to environmental additionality, other additionality criteria have also been proposed such as institutional, financial, and investment. See Carter (1997) for a discussion of these criteria. While these other kinds of additionality have been explicitly taken out of the CDM rules, alternative additionality criteria are explored in Langrock et al (2000), Meyers (2000), and Shrestha \& Timilsina (2002).

${ }^{4}$ In this paper, we account only for emissions of $\mathrm{CO}_{2}$, but we refer only to mass of carbon emitted. For the approximate mass of emissions of $\mathrm{CO}_{2}$, multiply the emissions or emissions rates by 3.67.
} 
setting a multiproject baseline is more transparent and readily available to all stakeholders than for project-specific baselines.

There are several rationales for exploring the use of MPBs as an alternative to project-specific baselines. Most importantly, they are more consistent and rely on a transparent approach, but another benefit is that developing multiproject baselines helps to minimize transaction costs while ensuring environmental integrity. The higher transaction costs of setting project specific baselines are likely to reduce the number of projects that attract investment, particularly for smaller renewable energy and energy efficiency projects. Experience with other project evaluations has shown that construction of project-specific baselines is time-consuming, costly, and can be highly uncertain ${ }^{5}$. Thus, the concept of using standardized benchmarks to calculate baselines across many projects, for particular sectors or given technologies, has emerged. MPBs are more consistent than project-specific calculations because the same data and methodology are used to set benchmarks to which all projects will be compared. These multiproject baselines can be used as an alternative to project-specific baselines in some carbon-trading schemes depending upon the preference of the regulator, host country, and/or project developer.

While it is usually understood that a project developer would set a project-specific baseline, it is less clear as to who would set a MPB. A MPB will typically be set by someone who is interested in seeking carbon reductions from many projects within a particular category. For grid-connected projects it may be the electricity grid operator or a consolidator of grid-connected projects. A consolidator may be an organization that would seek to coordinate relatively small projects and apply for certification for several projects at once. An industry association could act as a consolidator on behalf of its members for instance. A development bank may also act on behalf of its borrowers.

The aim of this paper is to illustrate the suitability of MPBs for grid-connected electricity generation and efficiency projects. We describe a standardized MPB and benchmarking methodology for electric power projects that uses MBase, a spreadsheet tool developed at the Lawrence Berkeley National Laboratory (LBNL). In this paper we focus more on the emissions rates rather than total emissions, since for a given level of project output, it is the difference between a project's rate of emissions and that of the displaced electricity that determines the credits received.

The multiproject baseline methodology is illustrated with two case studies that focus on several hypothetical but realistic electric power projects in India and South Africa. These include demand side energy efficiency, renewable energy, and fossil-fueled power plants. The two case studies are part of a broader set of studies of the use of MBase for electricity and industrial project applications. Two other case studies were conducted for the cement sector in Brazil and China (Sathaye et al. 2001). Data and information for the case studies were gathered in 2000. In the presentation below, we report on our current understanding of the advantages and disadvantages of the use of multiproject baselines.

\footnotetext{
${ }^{5}$ An evaluation of a number World Bank-managed Prototype Carbon Fund projects found that the costs associated with preparing a project-specific baseline study and presenting a case for environmental additionality are about US\$20,000 per project (World Bank, 2000). Uncertainty related to calculation of emissions reductions using project-specific baselines has been estimated to range from $\pm 35 \%$ to $\pm 60 \%$ for demand-side, heat supply, cogeneration, and electricity supply projects (Parkinson et al., 2001).
} 


\subsection{Application to the Electric Power Sector}

Electricity projects can displace either on-grid or off-grid electricity. Off-grid electricity is likely to be typically generated using a single power source, e.g., a diesel-fired generator. Estimating its likely emissions is much simpler compared to the estimation of emissions avoided from a mix of on-grid power plants. An electric power grid typically has different types of power plants that are operated simultaneously. Some are operated as baseload power plants at a high capacity factor, others as intermediate and peaking plants. The latter plants are operated as load-followers whose hours of operation are altered to meet the desired load at a given time of day.

In some cases, determining the emissions rates for grid-connected projects may be relatively straightforward. For example, the developer of a natural gas power project may claim that it offsets electricity from a coal power plant that would have been built instead. Assuming this claim is valid, we would estimate the additional emissions reductions from the power project as the difference in emissions between the coal and natural gas power plants. The coal plant could be a station planned by either the developer or utility company. If, however, in reality, the utility company's next planned station were a hydroelectric power plant, the developer would not be able to claim any carbon reduction. Unfortunately, the source(s) of electricity offset by a project often cannot be clearly identified.

Determining what sources of emissions are actually offset by GHG mitigation projects depends on constructing BAU scenarios. In order to estimate emissions offset by grid connected electricity projects, it is important to distinguish between average and marginal emissions rates. Average emissions rates equal the total carbon equivalent emissions over total electricity consumption for a grid. These are useful for estimating the emissions associated with a consumer's total use of electricity, such as for an emissions inventory. Marginal emissions rates are used to estimate the emissions avoided by a project that reduces the demand for electricity from existing plants (operating margin) or provides new generation from lower carbon sources than would otherwise be used (build margin). Since grid operation and capacity planning are extremely complex, determining the sources of electricity offset by a given project poses a major challenge.

Several methods and models have been developed to simulate the effects of various factors on both the operations and capacity planning of electric grids (see Kartha, Lazarus, and Bosi 2002 for a more in-depth typology and discussion of emissions rates methodologies). One approach to estimating average and marginal emissions rates for a grid is to use relatively sophisticated generation planning models, e.g., Elfin or WASP, that simulate future grid operation in order to meet a forecasted hourly load. This is the type of approach proposed by the US EPA for its online emissions profile tool (Kerr et al. 2002). As an alternative to these often costly and opaque models, LBNL has developed a relatively simple load-duration curve (LDC) spreadsheet to calculate average emissions rates and operating marginal emissions rates. This LDC spreadsheet was evaluated in case studies of grids in Brazil, Wisconsin, and California (Meyers et al., 2000; Marnay et al., 2002).

\subsection{Description of MBase Functions and Methodology}

The method used in MBase further simplifies the above approaches by calculating marginal emissions rates as the weighted averages of various categories of plants. Using the operating information on existing and/or planned units serving the grid allows MBase to generate several types of benchmarks. Build margins are calculated as the average emissions rates of recently built plants or those under construction, and the operating margin is estimated as the weighted average emissions of all existing load following plants serving the grid. The California analysis (Marnay 
et al. 2002) supported the use of the simple MBase approach. It illustrated that the Elfin model, the simplified LDC spreadsheet, and the weighted average of existing load-following plants produced similar results for the marginal emissions rates.

With estimated output and fuel consumption (where applicable) of GHG mitigation projects, MBase also calculates the annual carbon emission reduction credits that a project might earn. The benchmarks produced by MBase may also be used as a test for environmental additionality, at least in the case of fuel specific comparisons. These benchmarks can provide an indication of whether a fossil-fired project is environmentally additional by comparing its emissions rate to one of the more stringent benchmarks generated by MBase. Projects that perform better than these stringent levels could be assumed to result in the introduction of more efficient technologies than would have otherwise occurred and thus lower GHG emissions below baseline levels. The other types of additionality criteria are outside the scope of the MBase methodology and must be evaluated separately.

\section{Multiproject Emissions Rates}

The essential data required for estimating multiproject emissions rates (MPERs), are the fuel input (in GJ per year) and electrical output (in TWh/year) of all load-following plants and all recently built or planned baseload plants. Combining this information with the carbon content $(\mathrm{kg}$ $\mathrm{C} / \mathrm{GJ}$ ) of the fuel, we can calculate each plant's emissions rates in $\mathrm{kg} \mathrm{C} / \mathrm{kWh}$. These emissions rates are the key element for constructing the baseline MPERs. Once the baseline MPERs are constructed, a project's carbon emissions reductions are determined by multiplying the difference between the project's emissions rate and that of the chosen baseline MPER by the project's annual electricity production or savings (see Equation 1 below).

GHG Reduction $(\mathrm{kg} \mathrm{C})=($ MPER - project emissions rate $(\mathrm{kg} \mathrm{C} / \mathrm{kWh})) *$ annual project output $(\mathrm{kWh})--(1)$

\subsection{Five Key Decisions for Calculating Multiproject Emissions Rates}

Benchmark values depend heavily on decisions concerning five dimensions that determine which plants a project is compared to: geographic scope, generation type, vintage, breadth, and stringency. Ultimately, the certifying or executive body of a given carbon trading scheme must make these decisions, but below we describe the guidelines that were used for this analysis.

\subsubsection{Determining the Geographic Scope}

The first decision that needs to be made is the geographic scope of plants to include in the benchmark set. For industrial sectors, this may be global for technologies that are largely internationally standardized, or the scope may be national or regional for technologies whose production processes or fuel types vary. For the electricity sector, however, the scope should be determined by the extent of the grid since the emissions rates of electricity may differ substantially from one grid to another. In some cases grid regions may be clearly defined by remoteness and lack of interties to other grids. In cases where interties do exist, defining the grid region may depend on other criteria, such as whether or not a competitive wholesale power pool exists (see Lazarus, Kartha, and Bernow, 2000 for a discussion of this issue).

\subsubsection{Generation Type}

The generating resources that will be displaced by a project will depend largely on the type of project being proposed. Some projects provide intermittent power and may not always be able to 
generate power when needed. These types of projects are referred to as nonfirm power projects and may include sources such as solar and wind power or energy efficiency projects whose impact on demand are not predictable. These projects only obviate the need for power from existing sources. Thus, utility planners must still plan for new capacity despite additions of nonfirm generating resources. When these projects do supply power, they offset generation from load-following plants whose output is ramped down in response to electricity entering the grid. All existing load-following units should therefore be used to estimate a displaced emissions rate that will serve as the MPER for these projects.

We should note that some analysts propose excluding low-cost and must-run sources, such as hydro, geothermal, wind, and biomass residues from the operating margin algorithm (Kartha, Lazarus, and Bosi 2002). In our approach, we largely resolve this issue by placing most of these resources in the baseload reference set, including run-of-river hydro. Pondage hydro facilities, however, are often run to provide load-following power, i.e. at the times when the energy has highest value. Economic merit order dictates that, due to its very low marginal cost, hydropower be the last resource foregone in response to reductions in demand, and pondage energy will normally be saved for future use. We believe, though, that pondage hydro facilities may be affected by power from intermittent sources in some circumstances. ${ }^{6}$ Thus, whether pondage hydro should be entirely excluded from the operating margin calculation may depend on particular characteristics of the grid in question.

In contrast to nonfirm projects, firm capacity projects may affect marginal emissions by influencing the types of incremental power units being built more than the operations of existing units. This would be the case when increasing demand for electricity necessitates the construction of a new power plant and credits for reduced carbon emissions would fund the installation of a cleaner power source than would otherwise be built. This distinction between the impacts of new projects on the operations of existing plants and the impact on the types of plants being built has been referred to as the operating margin and build margin effects (Kartha, Lazarus, and Bosi, 2002).

The distinction between firm and nonfirm power will not always be so clear-cut. Some generating sources are able to provide a share of their total capacity reliably while output above that share is relatively unpredictable. This is the case for many hydro stations whose output is usually greater during rainy seasons or in the spring and early summer when river flows increase due to snowmelt. Annual variation in precipitation may also have large effects on total generation. Even wind farms may be able to reliably generate a small fraction of their capacity, depending on their size and location (Milligan et al. 2002). In cases where projects have both firm and nonfirm operating characteristics, capacity may need to be split into firm and nonfirm portions. Output up

\footnotetext{
${ }^{6}$ In most cases, even if some pondage hydroelectricity is foregone while it is on the margin, the water that would have been used to generate it is stored behind the dam for future use. However, grids marked by an exceptionally heavy dependence on hydro resources, such as in Brazil, may at certain times of the day or during certain seasons have no other resources to shed (Sathaye et al. 2001). The thermal capacity that is used on such grids may be needed for ancillary services such as voltage regulation, and may not always be ramped down even when, according to economic merit order, they should be. Environmental considerations may also dictate that a minimum level of river flow be maintained so that power from a pondage hydro facility foregone one day, will not be available for future use since the water must flow through the gates even though no power is generated. Finally, some countries may have made agreements to purchase hydropower at a premium from neighboring countries during peak periods, such as in Brazil (Sathaye et al. 2001), and would thus have an incentive to refrain from using this power.
} 
to a certain level would be compared to firm capacity baseline rates while additional generation would receive reduction credits based on the displaced emissions rate for nonfirm power.

Firm power generating sources consist of two distinct types of technologies: baseload plants that operate at very high capacity factors and load-following plants whose output fluctuates according to demand. Baseload plants tend to be large plants with low operating costs such as coal, nuclear, or large hydro. These plants require long lead times for construction. Load-following generators are generally smaller plants, often gas-fired or smaller hydro stations. Because of the differences in their emissions rates, baseload and load-following projects need to be evaluated separately, using reference plants of the same type.

These distinctions result in essentially three project types, which are shown below in Table 1, along with some representative examples.

Table 1. Project Types and Corresponding Multi Project Emissions Rates

\begin{tabular}{l|l|l|l}
\hline $\begin{array}{l}\text { Project Generation } \\
\text { Profile }\end{array}$ & $\begin{array}{l}\text { Nonfirm (intermittent or } \\
\text { unpredictable power } \\
\text { sources) }\end{array}$ & Firm Baseload & Firm Load-Following \\
\hline Project Examples & $\begin{array}{l}\text { Solar, wind, } \\
\text { small efficiency }\end{array}$ & $\begin{array}{l}\text { Large coal, hydro, or } \\
\text { combined cycle gas plant }\end{array}$ & $\begin{array}{l}\text { Gas turbine, } \\
\text { small hydro }\end{array}$ \\
\hline MPER Types & Operating Margin & Baseload Build Margin & $\begin{array}{l}\text { Load-Following Build } \\
\text { Margin }\end{array}$ \\
\hline $\begin{array}{l}\text { Plants Used For } \\
\text { MPERs }\end{array}$ & $\begin{array}{l}\text { All Existing Load- } \\
\text { Following Plants }\end{array}$ & $\begin{array}{l}\text { Recently Built Baseload } \\
\text { Plants }\end{array}$ & $\begin{array}{l}\text { Recently Built Load- } \\
\text { Following Plants }\end{array}$ \\
\hline
\end{tabular}

\subsubsection{Choosing the Vintage of Baseline Plants}

The third decision concerns the vintage of reference plants to use when constructing the MPERs. Because the operating marginal emissions rates are a function of the operation of existing load following plants, all load-following plants serving a particular grid are used to estimate the operating margin emissions rates. In contrast, estimating the build marginal emissions rates depends heavily on the assumptions about what types of plants are likely to be built in the future. The basic approach taken here is to separately examine the most recent baseload and loadfollowing plants added to the grid and to assume that the technologies and fuel sources used will be representative of the plants built in the near future. For some grids though, the plants that will be built over the next several years may be significantly different from those recently constructed. This may be the case if a new technology has been introduced or a new fuel source, such as gas, will become available.

As a general rule of thumb, we recommend using recently built plants for two main reasons. One advantage is that the data for such plants are observable, whereas the fuel types and performance of near-future plants can only be estimated. Another concern with near-future baselines is that they may be more susceptible to "gaming." Developers and host countries may have an incentive to claim that plants with high emissions rates are likely to be built in the future, so that projects will be able to earn more credits. Gaming can be avoided to some extent by including factors that are difficult to change, for example requiring the projection to be based on published government or utility plans. Setting regional baselines also makes gaming more difficult, as would a system of international review (Meyers, 2000). There is a trade-off between the risk of gaming and the risk of free riders benefiting from recently-built baselines that are overly lax compared to current standards. If recently built plants are used, a cut-off year must be chosen for plants to qualify as recently built. The cut-off year is somewhat arbitrary and may vary according to country-specific 
conditions although we suggest five years for the sake of consistency. Further work is needed to define appropriate guidelines for selecting the appropriate vintage.

Although we generally recommend the use of recently-built baselines, there are conditions that may favor the use of near-future baselines. Since electricity generation technology advances and diffuses relatively slowly, this choice between recently-built and near-future benchmarks will not generally have much effect on the resulting MPERs unless there is a possibility for significant fuel-switching in the near future. If lower-carbon fuels are available and have not yet been fully utilized, then a baseline using recently-built, more carbon-intensive, plants would provide excessive credits. If the current trend in the country, however, is to fuel-switch away from lower carbon fuels (e.g., in Brazil, where electricity generation is predominantly hydro but natural gasfired plants are being built in larger proportions) and future plans reflect this trend, then a recently constructed baseline would underestimate credits. Arguably, this type of baseline may also be a more accurate representation of the emissions that will be avoided by large projects that have long lead times. In this sense, a "near-future" baseline is likely to be methodologically more accurate while one based on recently constructed units is likely to have more accurate data. Finally, near-future baselines may need to be used in cases where there are insufficient data for constructing benchmarks based on recently built units. This was the case, for example, in South Africa where only one new plant had been built in the past seven years.

Where neither specifications for near-future plants are available nor sufficient data for recently built plants, project-specific scenario analysis may be required to best determine the likeliest source of new generation in the BAU case.

\subsubsection{Choosing Baseline Breadth}

The fourth issue for the build margin is which set of plants should be used for comparison to the proposed project - plants of the same fuel type only, plants of another specific fuel type, or an average of all plants. ${ }^{7}$ For firm capacity plants, it is not always evident what type of plant may be displaced by a project seeking emissions credits. For example, when demand growth requires the addition of a new baseload plant, a utility will generally try to construct stations with the lowest total cost to provide the needed electricity. The definition of what is least-cost may stretch beyond monetary costs and may include institutional and other costs as well, particularly where private and public players are in the market, which would make the decision on which plant to construct opaque. However, determining what is displaced may have a very large impact on the credits received. The decision concerning whether to use sector wide or fuel specific MPERs will likely be guided by additionality analysis. For a generation project to reduce emissions below the BAU case it must either more efficiently use the same fuel that would have been used in the BAU case or it must use a lower carbon power source. In cases where it can be clearly established that a project will replace another plant of the same fuel type using less advanced technology, a fuelspecific comparison would be appropriate. This might apply in a case where a utility is applying for GHG reduction credits to upgrade a coal-fired plant that is already in the planning pipeline to supercritical steam technology. ${ }^{8}$ However, in grid regions with multiple resource options for large plants (e.g. hydro, coal, and gas) it may be very difficult to determine what will be constructed in the BAU case.

\footnotetext{
${ }^{7}$ Neither the breadth nor the stringency decisions affect estimation of operating margin since this emissions rate reflects the actual emissions displaced from existing stations.

${ }^{8}$ Obviously, the fuel-specific comparison only works if there is at least one plant or unit in the benchmark set using the same fuel as the project.
} 
One way out of this dilemma is to take a weighted average of emissions rates of the recently built units, separated into baseload and load-following units, and use these rates as benchmarks for estimating baselines for all firm capacity power projects. Given the difficulty of determining what power sources are offset, we suggest that sector wide benchmarks be used as a default, although fuel specific MPERs may be calculated for cases in which it can be convincingly demonstrated that a project offsets a specific plant.

\subsubsection{Choosing Baseline Stringency}

The fifth decision to make when estimating MPERs for firm capacity projects is the stringency of the benchmarks. MBase generates four levels of stringency for firm capacity projects: weighted average, top $25^{\text {th }}$ percentile, top $10^{\text {th }}$ percentile, and best plant. The percentiles are calculated by ranking the plants within each fuel type from lowest emissions rate to highest and taking the emissions rate of the plant where 25 or 10 percent of the total occurs. This is done to prevent small plants from skewing the results. In order that the sector-wide percentiles not be largely a function of fuel type, the calculations in MBase are designed to have constant fuel shares. This is done by taking the percentile values within each fuel category and taking an average weighted by the contribution of each fuel type (including zero-emission sources) to total generation.

Recall that only the weighted average emissions rate of all existing load-following units is calculated as the MPER for nonfirm projects, since the goal is to approximate the emissions of power actually displaced from existing load-following units. There is little justification for using a higher stringency since these projects can come on-line quickly and the average emissions rate of load-following units is unlikely to change significantly in a few years' time.

The choice of stringency level for firm capacity plants, however, may profoundly affect the amount of emissions reduction credits a project will earn. For our analysis, the choice of stringency depended on whether "recently built" or "near-future" units are used to estimate the MPER. Where "recently built" units are used, it is appropriate to use more stringent criteria, such as the top 25th or 10th percentile, since projects seeking credits should perform better than the best existing plants to qualify. In cases where a fuel-specific comparison has been determined to be appropriate, even the "best plant" level may be used. ${ }^{9}$ Where "near-future" units are used to estimate the MPER, the weighted average value may be an appropriate benchmark, since plants under development are not likely to deviate much from the current state of the art for a given type of plant and will thus be comparatively efficient.

\subsection{Framework for Setting Multiproject Emissions Rates}

Based on the above discussion, Figure 1 shows a framework that can be used to guide project consolidators in choosing reference plants and selecting stringency levels for the three types of MPERs: baseload, load-following, and nonfirm. First, the reference set of plants should be divided into baseload and load-following plants, since separate emissions rates will need to be determined for these categories. Additionally, within the baseload and load following categories it may be helpful to separate fossil fuel plants by fuel types to estimate fuel-specific MPERs for those cases where it can be determined with some certainty that plants of a particular fuel type are

\footnotetext{
9 "Best plant" stringencies are not calculated for sector-wide comparisons since this is mostly a function of fuel type and not the efficiency of energy transformation. In most cases, a sector-wide best plant benchmark will be equal to zero since most grid systems will have at least one hydro plant or other zero emitting energy source.
} 
being offset by a project. Since this is often difficult to determine in practice, in most cases all baseload or load-following plants will be used.

If the project provides nonfirm power, the emissions rate should be based on the average of all load-following plants since it is assumed that the project will displace power from currently operating stations. For firm capacity projects, however, project consolidators must decide whether to use recently built or near-future plants to construct MPERs. If there is a sufficiently large sample of plants, we recommend using the "recently built" plants both because the emissions of these plants are based on verifiable historical data and using existing plants can help to minimize gaming of the baseline. One important consideration in choosing between these two options is to determine if the fuel mix is likely to change significantly in the future. The fuel mix of plants under construction may be used to provide a clue to this trend. A significant change in the fuel mix would favor the use of a near-future baseline. The rationale here is that the fuel mix change sufficiently affects the average emissions rate to justify the risk of gaming posed by using a nearfuture baseline. If no plants have been constructed recently, and data are available for near-future units, then a near-future baseline may be set. If these data are not available, then there is no choice but to construct a project-specific baseline. The final decision is to select a stringency level if you are using a recently built build margin baseline. For the recently-built sample of plants, we recommend choosing either the 25 th or 10 th percentile (this may depend on conditions specific to the particular grid region) to represent the baseline, and for the near-future units using the sectorwide weighted average as the baseline.

Once a project consolidator has calculated these rates, the project developer would use the appropriate MPER for their project type. If the developer of a firm capacity project believes that the project is offsetting capacity of a particular fuel type, then he or she may make the case that a fuel-specific MPER should be used. 
Figure 1: Framework for Choosing Reference Plants and Stringency Levels for GridConnected Electricity Projects

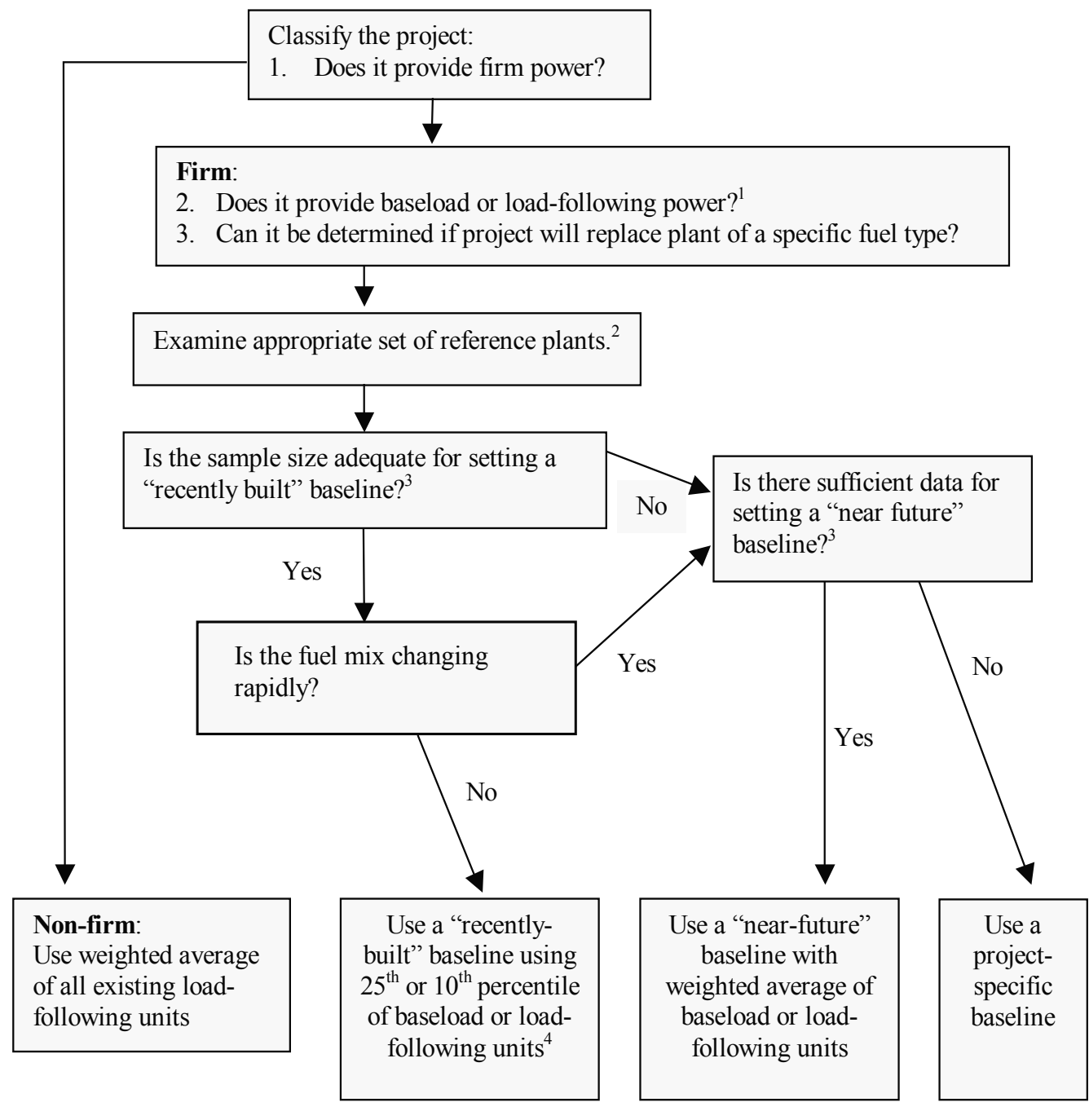

\footnotetext{
${ }^{1}$ Baseload project: One that offsets planned capacity and is designed to generate electricity $70 \%$ of the time or more annually.

2 According to the project type, this would either be all recently-built/near-future baseload plants, recently-built/near-future baseload plants of a specific fuel type, all recently-built/near-future loadfollowing plants, or recently-built/near-future load-following plants of a specific fuel type.

3 Adequacy requires at least one plant of each fuel type in the sample mix of baseload and loadfollowing units

${ }^{4}$ A stringent baseline could be either of the top percentile levels or, for fuel-specific comparisons, the best plant in the reference set.
} 


\subsection{Revisable Baselines}

Depending on the rules of a particular emissions trading regime, baselines may either be static or revisable. Static baselines are set at the time of project approval and remain unchanged for the duration of the crediting period, while revisable baselines are updated to reflect changes in the BAU conditions. For example, the current draft of the CDM guidelines offers developers the choice between a fixed baseline good for ten years and a revisable baseline that is adjusted every seven years and can be renewed twice. In cases where a revisable baseline is chosen, the MPERs can be adjusted by simply entering new data into MBase and re-running the analysis.

\section{Application of Multiproject Baselines for Evaluation of Electric Power Projects in India and South Africa}

In this section, the methodologies discussed above are applied to hypothetical projects in eastern India and South Africa. Coal is the dominant source of electric power in both regions, but other characteristics of these two grids differ considerably. While eastern India has added substantial capacity in recent years (about a third of total capacity since 1994), in South Africa only one plant has been built since 1996. This difference has important ramifications for baseline determination, which are discussed below.

\subsection{India Case Study - Eastern Regional Electric Power Grid}

With 243 million metric tons of carbon released from the consumption and flaring of fossil fuels in 1999, India ranked fifth in $\mathrm{CO}_{2}$ emissions from these sources in the world behind the United States, China, Russia and Japan (U.S. Energy Information Administration, 1999). Additional coal-fired plants are planned in order to satisfy the growing demand for electricity. During the last 25 to 30 years, the capacity share of large hydro has declined, while that of nuclear power is growing slowly. Currently, thermal plants, mostly coal-based, account for 72.9 percent of the total power generation, while hydro and nuclear power plants contribute 15.2 percent and 2.5 percent, respectively. The abundance of coal (India's coal reserve is estimated to be 2000 billion metric tons) coupled with a short construction period of three to four years for smaller thermal plants with a capacity below $250 \mathrm{MW}$, and between six to seven years for plants above $250 \mathrm{MW}$ capacity, has encouraged coal-powered generation in the country.

The plant capacity factor is very low in India (average is approximately 65 percent), and thermal efficiency varies across plants due to various grades of coal and a range of plant vintages. Thermal efficiencies range from approximately 25 percent to 40 percent. The high average age of thermal plants in India (about 30 years) and the use of high-ash-content coal reduce efficiency compared to many other countries.

The electricity distribution network in India is divided into five regions: north, west, south, east, and north-east. This case study focuses on the eastern region, which covers three states - West Bengal, Bihar, and Orissa. Though public, private, and government-owned public sector undertakings (PSUs) ${ }^{10}$ are all engaged in power generation, transmission, and distribution in the eastern region, the power industry in this region is dominated by the PSUs. Total installed capacity in this region is $16,973 \mathrm{MW}$, which is 15 percent of India's total. Six PSUs in this region

10 Public sector undertakings are public-private partnerships in which the government maintains a controlling interest. 
own 57 percent of the total regional generation capacity, the public sector owns 29 percent, and the remaining 14 percent is owned by the Calcutta Electric Supply Corporation (CESC), the only private licensee in this region. The regional power grid in the eastern region is governed by the Eastern Regional Electricity Board (EREB), which facilitates the flow of power from surplus to deficit areas and assists in its optimum utilization. Total consumption in the region for fiscal year 1999 - 2000 was 46,165 gigawatt hours (GWh).

Eastern regional electric generating capacity is based on two primary resources: coal and hydro. Ninety percent of India's coal reserves are located in the eastern region, which has led to a higher concentration of coal-fired plants there than in other regions. In 2000, there were 25 thermal power plants with 44 major generating units in the eastern region. ${ }^{11}$ Eighteen baseload units with a total capacity of $5650 \mathrm{MW}$ (33 percent of the total existing capacity) have begun operation since 1994. These eighteen units, all of which are coal-fired, constitute the basis for the estimation of the baseload MPER for the eastern regional electricity grid. The recently built loadfollowing units used to construct benchmarks for firm capacity load-following projects consist entirely of small hydro stations. Since the MPER in this case is equal to zero, no firm-capacity load-following projects can receive credits unless a developer can demonstrate that a thermal load-following unit will be built in the BAU case. In addition to the recently built hydroelectric stations, other load-following units used to estimate the emissions of power displaced by nonfirm units include other older hydro stations as well as four high-speed diesel-based gas turbines.

The 2003-13 expansion plans propose to construct 26 power stations with a total capacity of $24,313 \mathrm{MW}$ of which 72 percent will be coal-fired, 24 percent will be hydro, and 4 percent pumped storage. Although this is a higher share of hydro for the entire sector than a sample of recently built plants it will still be used almost entirely for load-following so the respective baseload and load-following MPERs will not be affected by the aggregate fuel switch. In addition to the large number of plants built since 1994, the fact that no major change is expected in the fuel mix indicates that benchmarks based on recently built plants may be reliably used.

Table 2 provides the MPERs for the three project types. All baseload thermal plants in the eastern region use coal as a primary fuel, but oil is also used either for boiler start-up, to supplement a shortage of coal supply, or to compensate for the unavailability of coal racks. ${ }^{12}$ Ordinarily, fuel oil consumption in coal plants is small and need not be accounted for because start-up fuel oil constitutes such a low share of total energy consumption. In this region, however, fuel oil use in most units exceeded five percent of total fuel use, and the average for all the coal plants in our benchmark set was 18 percent. Due to this use of mixed fuels, fuel-specific MPERs for coal could not be determined, except a "best plant" rate based on the one plant that reported no oil consumption.

The sector-wide baseload emissions rates decline dramatically with increasing stringency levels (see Table 2). This is due to the extremely low conversion efficiencies of four plants in the reference set. The rates for firm load-following projects are all zero because only small hydro stations have been built in recent years to supply firm load-following power. The operating margin emission rate used for nonfirm projects is slightly higher than zero because the diesel oil turbines generate such a low share of load-following power that they have almost no effect on the average emissions rate.

\footnotetext{
${ }^{11}$ A power plant may have more than one unit with different vintages.

${ }^{12}$ Coal may not be available at times during the rainy season when it becomes too drenched for use in the boilers.
} 
Table 2. Baseline Multiproject Emissions Rates for the Eastern Grid in India (kg C/kWh)

\begin{tabular}{l|c|c|c|c}
\hline Project Type & $\begin{array}{c}\text { Weighted } \\
\text { Average }\end{array}$ & $\begin{array}{c}\mathbf{2 5}^{\text {th }} \\
\text { Percentile }\end{array}$ & $\begin{array}{c}\mathbf{1 0}^{\text {th }} \\
\text { Percentile }\end{array}$ & $\begin{array}{c}\text { Best } \\
\text { Plant }\end{array}$ \\
\hline Baseload: Sector-wide & 0.346 & 0.316 & 0.217 & N/A \\
Baseload: Coal Only & N/A & N/A & N/A & 0.300 \\
Load Following & 0.000 & 0.000 & 0.000 & 0.000 \\
Nonfirm & 0.001 & N/A & N/A & N/A \\
\hline
\end{tabular}

Table 3 presents information on three hypothetical climate change mitigation projects that could be proposed as alternatives to utility generation, as currently planned. All three project types are represented. Project 1 is a coal project with capacity of $1000 \mathrm{MW}$ that will provide firm baseload capacity. It is more fuel-efficient and will use better quality coal, and with less oil input, than existing plants. Project 2 is a hydroelectric project with capacity of $200 \mathrm{MW}$ that will provide firm load-following capacity. Project 3 is based on plans proposed by the Renewable Energy Development Agency for decentralized supply of $6 \mathrm{MW}$ of solar generating capacity. Since the baseload plants used for benchmarking are recently built plants, we chose the $25^{\text {th }}$ percentile level of stringency because new plants should perform better than the average of existing plants (see Figure 1). Project 1 performs better than the weighted average and $25^{\text {th }}$ percentile, but it does not reduce carbon emissions when the $10^{\text {th }}$ percentile baseline is used since the best plant in the benchmark set, which generates more than 10 percent of the power from these plants, has an emissions rate of $0.217 \mathrm{~kg} \mathrm{C} / \mathrm{kWh}$. Table 3 shows that Project 1 receives the most credits since it both generates a large amount of power and has an emission rate well below the benchmark rate. Project 2 receives no credits since the reference benchmark rate is zero. The solar project receives virtually no credits due to the low displaced emissions rate and small size of generation.

Table 3. Hypothetical climate change mitigation projects

\begin{tabular}{l|c|c|c|c}
\hline & & Project 1 & Project 2 & Project 3 \\
\hline Fuel & & Coal $^{\mathrm{a}}$ & Hydroelectric & Solar \\
Capacity & $(\mathrm{MW})$ & 1000 & 200 & 6 \\
Type & & Baseload & Load-Following & Nonfirm \\
Annual generation & $(\mathrm{TWh})$ & 6.132 & 0.701 & 0.006 \\
Emissions rate & $\mathrm{kg} \mathrm{C} / \mathrm{kWh}$ & 0.220 & 0.000 & 0.000 \\
Benchmark rate $^{\text {GHG Reductions }}{ }^{\mathrm{c}}$ & $\mathrm{kg} \mathrm{C} / \mathrm{kWh}$ & $0.316^{\mathrm{b}}$ & 0.000 & 0.001 \\
\hline Coal $^{\mathrm{k}}$ & $\mathrm{kt} \mathrm{C}$ & 591 & 0 & 0.006 \\
\hline
\end{tabular}

${ }^{a}$ Coal power plant uses $1 \%$ fuel oil for boiler start up

b Baseload $25^{\text {th }}$ percentile.

c Credits shown in kilotonnes carbon equivalent, calculated as annual generation times the difference between benchmark rate and the project's emissions rate (see Equation 1).

\subsection{South Africa ${ }^{13}$}

The electricity supply industry in South Africa is almost entirely owned by the public sector either through the state-owned company, Eskom, or through municipal distributors. Eskom dominates generation and transmission. There are a few self-producers, some of which sell to

${ }^{13}$ Based on Winkler, et al., 2001. 
neighboring communities. Eskom owns 92 percent of all generation capacity in South Africa, municipalities own 6 percent and private generators only 2 percent. The net electricity delivered to the grid in South Africa in 2000 was 194 TWh (NER, 2000). South Africa's electricity generating technology is based largely on coal-fired power stations, mostly owned and operated by Eskom and largely concentrated near and to the east of Johannesburg - close to the main coal resources as well as the country's major demand center. At the end of 2000, there were 50 power stations in operation in the country, of which 20 were coal-fired. Coal-fired power stations (Eskom and municipal) accounted for 89 percent of the total capacity of 43,142 MW (excluding capacity in reserve and under construction) and 93 percent of net electricity. Three of Eskom's older coal stations are currently in reserve ("mothballed") because of excess capacity, and these would add an additional 3,556 MW. The only non-coal stations of significance are the Koeberg nuclear power station (4 percent of operational capacity) and three pumped storage facilities (4 percent of operational capacity) (NER, 2000).

The average age of Eskom's operational power stations is 14 years (weighted by capacity); several large stations constructed in the 1980s heavily influence this figure. Eskom's coal-fired power stations generally exhibit high thermal efficiencies for conventional pulverized fuel technology. Average thermal efficiencies have consistently been more than 34 percent, despite the use of low quality (high ash) coal and the use of dry-cooling technology on two newer plants, which is slightly less efficient than wet-cooled stations (Eskom, 2000b). The weighted average heat content of coal used for power generation is low at $21.3 \mathrm{GJ} / \mathrm{t}$ (coal) compared to the IPCC default value of 29.3; carbon content is relatively high at $26.2 \mathrm{tC} / \mathrm{TJ}$ compared to the IPCC factor of 25.8 (IPCC, 1995). Eskom's mothballed stations are 30 years old on average and would typically have lower than average thermal efficiencies. The dependence on coal means that South Africa's electricity industry had relatively high GHG emissions, with Eskom releasing 43.9 MtC in 2000 (Eskom 2000b). The average $\mathrm{CO}_{2}$ emissions rate is about $0.23 \mathrm{kgC} / \mathrm{kWh}$ (ibid.).

Although using observed data from recent plants reduces gaming, and is probably desirable for baselines in many electricity sectors, in South Africa, only one baseload power station, Majuba, has been constructed in the last seven years. ${ }^{14}$ At Majuba, six units were constructed from 19962001. If one uses the "recent plant" approach, one therefore compares the proposed projects to the performance of a single power station. The slower growth in demand in South Africa in recent years creates some inertia against changes in the capacity mix. Opportunities to change the capacity mix towards low-carbon technologies are constrained by the existence of excess capacity and mothballed coal stations. In this analysis, we have therefore chosen a baseline for baseload plants that includes six "near-future" power plants.

Table 4 presents information on these plants, which include the two new units of Majuba, the recommissioning of two units in mothballed power stations, a new natural gas plant and imported hydroelectric power (Eskom, 1996; Eskom, 2000c; Eskom, 1999; NER, 2000). The capacity factors for the Majuba units are in the range of load following stations due to limited coal resources near the power station and consequent high variable costs. Given the directions set by Eskom's Sixth Integrated Electricity Plan, one could reasonably expect the five indigenous units and imported hydro to come on line between 2000 and 2005 (Eskom, 1998b).

14 The last previous plant was Kendal, whose units were commissioned from 1988-1993 (Eskom 1996). 
Table 4. Six near-future firm capacity electricity generation plants in South Africa used for development of near-future baseline MPERs

\begin{tabular}{l|c|c|c|c|c|c|c}
\hline & & $\begin{array}{c}\text { Plant } \\
\mathbf{1}\end{array}$ & $\begin{array}{c}\text { Plant } \\
\mathbf{2}\end{array}$ & $\begin{array}{c}\text { Plant } \\
\mathbf{3}\end{array}$ & $\begin{array}{c}\text { Plant } \\
\mathbf{4}\end{array}$ & $\begin{array}{c}\text { Plant } \\
\mathbf{5}\end{array}$ & $\begin{array}{c}\text { Plant } \\
\mathbf{6}\end{array}$ \\
\hline Fuel & & $\begin{array}{c}\text { Mothballed } \\
\text { Coal }\end{array}$ & $\begin{array}{c}\text { Mothballed } \\
\text { Coal }\end{array}$ & $\begin{array}{c}\text { Natural } \\
\text { gas }\end{array}$ & $\begin{array}{c}\text { New } \\
\text { Coal }\end{array}$ & $\begin{array}{c}\text { New } \\
\text { Coal }\end{array}$ & $\begin{array}{c}\text { Imported } \\
\text { hydro }\end{array}$ \\
\hline Type & & Baseload & Baseload & Baseload & $\begin{array}{c}\text { Load } \\
\text { Following }\end{array}$ & $\begin{array}{c}\text { Load } \\
\text { Following }\end{array}$ & $\begin{array}{c}\text { Load } \\
\text { Following }\end{array}$ \\
\hline Capacity & $(\mathrm{MW})$ & 570 & 870 & 736 & 713 & 713 & 400 \\
\hline Annual generation & $(\mathrm{TWh})$ & 3.02 & 4.61 & 4.13 & 0.83 & 0.83 & 1.84 \\
\hline Emissions rate & $\mathrm{kg} \mathrm{C/kWh}$ & 0.315 & 0.315 & 0.100 & 0.274 & 0.274 & 0.000 \\
\hline
\end{tabular}

For the nonfirm capacity load-following projects we use the existing peaking stations. In South Africa, most of these stations are either hydro or pumped storage. However, the high preponderance of coal stations implies that some coal stations are also used for load following. Plants with capacity factors of less than 60 percent were assumed to operate as load-followers, and include large coal fired power stations. These plants consist of a few smaller, older stations owned by municipalities and three large coal stations owned by Eskom, including the units at the Majuba plants that have been run at low capacity factors due to the higher cost of coal used for that station. Additionally there are two oil-fired gas turbines with a combined capacity of 342 MW, but they are used only in emergency situations (NER 2001).

Table 5. Baseline Multiproject Emissions Rates (Weighted Average) Using "Near-Future" Electricity Plants in South Africa (kg C/kWh)

\begin{tabular}{l|l}
\hline Project Type & MPER \\
\hline Firm Baseload: Coal (2 plants) & 0.315 \\
Firm Baseload: Natural Gas (1 plant & 0.100 \\
only) & 0.239 \\
Firm Baseload: Sector-wide & 0.130 \\
Firm Load-Following: Sector-Wide & 0.246 \\
\hline Nonfirm: Operating Margin &
\end{tabular}

Table 5 provides the multiproject sector-wide and fuel-specific MPERs based on "near-future" plants as well as the displaced emissions rate for nonfirm projects. Only weighted average MPERs are shown for firm capacity projects since near-future plants were used. An interesting result of the analysis is the disparity between the displaced emissions rate used for nonfirm projects (i.e. the operating margin) and the weighted average benchmark for firm capacity loadfollowing projects (the build margin). This results from the presence of pumped storage units (which are assigned an emissions rate of baseload coal corrected for conversion losses) and older, inefficient coal plants in the existing load-following generation mix. Thus, nonfirm power projects will receive substantially higher credits per $\mathrm{kWh}$ displaced than firm capacity loadfollowing projects. 
Table 6. Four hypothetical electricity generation projects in South Africa

\begin{tabular}{lc|cccc}
\hline Fuel/Project & & Project 1 & Project 2 & Project 3 & Project 4 \\
\hline Project Type & Natural gas & Coal & Wind & $\begin{array}{c}\text { Compact } \\
\text { Fluorescent } \\
\text { Bulbs }\end{array}$ \\
Capacity & & Baseload & Baseload & Nonfirm & $\begin{array}{c}\text { Load- } \\
\text { Following }\end{array}$ \\
Annual generation & $(\mathrm{MW})$ & 368 & 1,974 & 5 & $1,080^{*}$ \\
Emissions rate & $\mathrm{kg} \mathrm{C} / \mathrm{kWh}$ & 0.100 & 0.201 & 0.014 & $2.66 *$ \\
Benchmark rate & $\mathrm{kg} \mathrm{C/} \mathrm{kWh}$ & 0.239 & 0.239 & 0.246 & 0.000 \\
GHG reductions & $\mathrm{ktC}$ & 287 & 403 & 3.4 & 0.130 \\
\hline
\end{tabular}

* Avoided capacity and generation.

Sources: Roggen (2000), Howells (1999), Eskom (2000a), Spalding-Fecher et al. (2002), SpaldingFecher (2002).

Table 6 presents information on four hypothetical projects. Project 1 is based on importing gas from the Kudu Gas fields for three units of 368 MW each (Roggen 2000). Project 2 is based on the use of a more efficient, super-critical steam coal plant (Howells 1999). Project 3 is the Darling wind farm, a plan to install 5 MW capacity for the grid (Spalding-Fecher 2002). Project 4 is an Eskom initiative to install 18 million compact fluorescent lights (CFLs) to reduce energy demand in the residential sector (Eskom 2000a; Spalding-Fecher et al 2002). The multiproject approach may be used to measure emissions reductions brought about by an energy efficiency option as well as supply-side options against the same multiproject baseline. End use efficiency projects should be credited with additional credits since, due to transmission and distribution losses, demand side measures save more electricity from being generated than is avoided the outlet. The generation avoided of $2.66 \mathrm{TWh}$ shown in Table 6 assumes average transmission and distribution losses of 11 percent (Spalding-Fecher et al., 2002). Given the size of this project, it was treated as a firm capacity provider since the distribution of this number of CFLs results in annual power savings that Eskom should factor into its future generation capacity mix.

Although Project 2 receives credits at the lowest rate of any of the projects studied, due to the quantity of its expected output it would receive the most credits of the projects shown. Project 1 , a natural gas plant, receives credits at a much higher rate but is also a smaller capacity unit than Project 2. Project 3 is much smaller than the others in terms of capacity and as a wind farm would operate at a much lower capacity factor. However it does benefit from a high displaced emissions rate of load-following units. Project 4, which benefits from the adjustment for transmission and distribution losses, would also received a large number of credits.

\section{Discussion}

\subsection{Effect of Methodological Choices}

\subsubsection{Segregating the Generation Type}

In the eastern Indian grid region, calculating different MPERs for the baseload and loadfollowing projects has a profound effect on the estimation of credits generated. Due to this 
distinction, we found that projects that displace power from existing load-following units would receive no credits for reducing GHGs. In sharp contrast, the baseload units of this grid are all coal-fired and many of them are operated at very low efficiencies resulting in high emissions. Thus the introduction of the baseload gas unit would have a much larger impact on reducing GHGs than a similar project designed to produce load-following power. Since virtually all of the existing load-following capacity is hydro and there are currently no plans to introduce thermal load-following units, there was only a negligible difference between operating and build margins of load-following units.

In South Africa, the difference between the build margin of baseload and load-following units was not so sharp, although at more than $0.1 \mathrm{~kg}$ of carbon per $\mathrm{kWh}$ the difference is still significant. Interestingly, the operating margin was almost the same as the build margin of the baseload units because of the use of coal power stations as load following plants. Although there is significant hydro contribution to load-following power, the resulting average emissions rate is raised substantially by the assumption that coal units that run at low capacity factors are operated as load-following units. The presence of some pumped storage also raises the average.

\subsubsection{Choosing Vintage of Baseline Plants}

"Recently built" electric generation plants were chosen for construction of the Indian (eastern regional grid) baseline, where 25 power generation units, accounting for approximately 33 percent of total generating capacity, were constructed between 1994 and 2000. These recent plants reflect a variety of fuel types, including coal, wind, and hydro. Not only were ample data available to construct the baselines, the near-future plants are also of similar mix in terms of fuels and capacity. Therefore, the performance of the "recently built" plants has been selected as representative of a baseline MPER.

In South Africa, it was not possible to construct a baseline of "recently built" plants since only one power plant has been constructed in the last seven years. To use historical data, one would have to go back some 20 years or so to get a reasonably representative baseline. That would defeat the purpose of using only recent plants to represent current technological standards and fuel mix trends for the region. For this analysis, a baseline looking at three "near-future" options for baseload power and three options for load-following power were used. The South Africa case study showed that, at least for highly centralized power systems, it was not difficult to find information on near-future plants for the electric power sector, where plans for capacity addition are commonly available.

\subsubsection{Choosing Baseline Breadth}

In India, baseline breadth was not much of an issue since baseload and load-following power are each dominated by one generation source. Estimating fuel specific benchmarks for coal plants was complicated by the fact that plants in this region burn such relatively large shares of oil.

In South Africa, the addition of a natural gas plant as a potential baseload project in the reference set has a large impact on the sector wide average. If the gas plant is deemed an unlikely option, then the coal project would be compared to the much higher fuel specific coal baseline and would therefore receive more than three times as many credits. This shows the importance of careful selection of baseline breadth and the challenges of using a near future baseline. 


\subsubsection{Choosing Baseline Stringency}

As noted in Section 2.1.5, the use of more stringent MPERs is justified when using a sample of "recently built" units to estimate a baseline, as in the India case. However, choosing between the 25 th and 10th percentile levels is a decision that will depend on local circumstances. The effect on credits received can be substantial. The emissions reductions per $\mathrm{kWh}$ estimated for the coal project in Section 4.1.2 fall from $0.096 \mathrm{~kg} \mathrm{C} / \mathrm{kWh}$ to zero when increasing stringency from the 25 th to the 10th percentile level (see Table 2 and Table 3 ). In a slowly expanding grid with few new plants being added, the average age of power plants will be high, which would suggest using a $10^{\text {th }}$ percentile level of stringency and vice versa. For India, the average age of our sample of "recently built" power plants was only about five years, and hence we chose the $25^{\text {th }}$ percentile level as the benchmark. ${ }^{15}$

For the South Africa case, we used sector-wide averages to set a baseline since the baseline included near-future plants. Calculating stringency levels would not have been an option in any case for either baseload or load-following MPERs due to the small number of plants in each sample.

\subsubsection{Using MBase to Establish Environmental Additionality}

Above, we discussed the possibility of using fuel-specific MPERs as performance benchmarks for additionality testing. Projects whose emissions rates are lower than that of other recently built or near-future plants of the same fuel type may be assumed to be introducing more efficient technologies. This could be a single plant (best plant) or a combination of plants at the $10^{\text {th }}$ percentile level. All renewable energy and energy efficiency projects automatically satisfy this environmental additionality test since they have zero GHG emissions.

In the India case, the emissions rate of the coal project is slightly greater than that of the best existing coal plant (which also constitutes the $10^{\text {th }}$ percentile benchmark), rendering the proposed project "not additional" (see Table 2 and Table 3). In the South Africa case, the emissions rate of the natural gas plant equals that of the gas plant under discussion, while the advanced coal plant performs much better than the recently built units at the Majuba plant (see Table 5 and Table 6). Thus, only the coal plant would qualify using these benchmarks as additionality criteria.

\subsection{Data}

One question that comes up often regarding multiproject baselines is the degree of difficulty of getting the data for different plants. Generally, data for the electricity sector are reliable because plants are typically required to collect and report their output and fuel consumption to regulatory agencies. These data are usually easy to obtain, in part because in most countries the plants are publicly owned. Obtaining the data may become increasingly difficult as more countries begin to privatize their generation assets and allow independent power producers to enter the market. However, complications arise for utility-owned plants as well. In the Indian case, several plants had generating units that were commissioned in different years, but the generation and fuel consumption data were originally provided only at the plant level. The emissions rates of some

\footnotetext{
${ }^{15}$ Additional work is needed to develop a rule about which percentile baseline to use. The percentile will depend on the rate of capacity turnover in the grid baseline.
} 
plants were increased by the presence of older units that, due to their vintage, should have been excluded from the reference set. Additional research was required to obtain the unit-specific data.

In South Africa, some of the data required is published by the National Electricity Regulator (NER 2000). As in other countries, however, the detail of published data has tended to decrease over the years, compared to earlier statistics. ${ }^{16}$ With power sector reform being actively discussed, information is increasingly treated as confidential. Particular data problems for baselines relate to plant-specific efficiency and fuel consumption, which are difficult to obtain. However, data relating to plants' licensed capacity, maximum power produced, gross and net energy sent out, own use in generation process, own use for private consumption, and capacity factors are still published.

\section{Conclusions}

Multiproject baselines offer significant advantages compared to separate estimation of projectspecific baselines by developers. Since the burden for estimating GHG emissions reductions is shifted to the regulatory entity of a given carbon trading scheme or another project consolidator, the availability of MPERs can significantly reduce transaction costs for developers. Multiproject baselines also offer advantages over the use of complex models to set baselines since they are more transparent and simpler to use.

There are several decisions, however, that must be made to construct and use MPERs. First, it must be decided which plants to include in the benchmark set. Using "recently built" plants, as in the Indian case study, may often be preferable since benchmarks are based on actual performance data. Circumstances in South Africa, however, showed that this is not always possible. In these cases, units planned for the near future or a combination of "recently built" and "near-future" units may be used. The credits ultimately generated by each approach should not differ greatly, as long as benchmarks are dynamic, that is, as long as they are revised every few years. We found that estimating MPERs separately for baseload, load-following, and nonfirm projects can yield large differences. We conclude that distinguishing between the operating margin and build margins of baseload and load-following plants is important to produce reasonably accurate estimates of a project's impact on emissions.

The issue of baseline breadth and stringency is complex. If it were possible to know the type of plant that would be offset by any particular project, these choices would be clearer. Since this is rarely the case, by default, firm capacity projects will often be compared to a sector-wide combination of other baseload or load-following units, depending on the type of project. Smaller nonfirm capacity projects' emission reductions will be determined using the average emissions rate for the load-following units as an approximation of the operating marginal emissions rate. The choice of stringency is ultimately somewhat arbitrary, but higher stringencies will be justified when the reference set is comprised of recently built plants, as opposed to near-future ones.

Overall, these case studies show that it is important to fully evaluate the variety of potential baselines in order to make informed decisions regarding which plants to include in the baseline, what type of baseline to use (baseload, load-following, or operating margin), and what level of stringency to use. The case studies presented in this paper represent an initial effort to develop and test the concept of multiproject baselines for the power sector. Further research is required to

\footnotetext{
${ }^{16}$ Electricity statistics were published by Eskom until 1996, when the NER took over publication.
} 
fully understand the ramifications of the various choices in constructing and using these baselines. In particular, the following topics should be explored further:

- Incorporating more sophisticated modeling of plant and project operations to account for variation in MPERs by (1) season (e.g., fluctuation in hydropower as a share of grid generation), and (2) time of day, while bearing in mind that the approach still needs to be transparent and least cost.

- Making more detailed comparisons of multiproject against project-specific baselines, as applied to specific projects, which may require additional project-specific studies.

- Assessing the implications of choices among the five key decisions.

- Evaluating the impacts of the cumulative generation of several small nonfirm projects on the build margin.

- Defining rules for assigning portions of nonfirm projects' reliable generation to the build margin baselines.

- Establishing clearer criteria for selecting baseline stringencies, years for vintages, and choosing recently built plants versus near future baselines.

\section{Acknowledgments}

This work was supported by the U.S. Environmental Protection Agency Office of Air and Radiation / Office of Atmospheric Programs through the U.S. Department of Energy under Contract No. DE-AC03-76SF00098. The authors would like to thank Amol Phadke (LBNL) for his review of the India case study and Chris Marnay (LBNL) for his comments.

\section{References}

Carter, L. 1997. Additionality: The USIJI Experience. Paper presented at the Workshop on Environmental Benefits of AIJ, 9-10 September, Paris, IEA.

Chomitz, K M 2002. Baseline, leakage and measurement issues: how do forestry and energy projects compare? Climate Policy 1: 1-15.

Ellis, J. and Bosi, M., 1999. Options for Project Emissions Baselines. OECD and IEA Information Paper. Paris: Organization for Economic Co-operation and Development and International Energy Agency.

Ellis, J., 2000. An Initial View on Methodologies for Emission Baselines: Cement Case Study. OECD and IEA Information Paper. Paris: Organization for Economic Co-operation and Development.

Eskom, 1996. Eskom Statistical Yearbook,. Sandton, South Africa: Eskom.

Eskom, 1998b. IEP6: Integrated Electricity Plan for the Period 1997 - 2016. Sandton, South Africa: Eskom.

Eskom 1999. Environmental Report 1999. Sandton, South Africa: Eskom.

Eskom, 2000a. Efficient Lighting Initiative. Sandton, South Africa: Eskom.

Eskom, 2000b. Environmental Report 2000: Towards sustainability. Sandton, South Africa: Eskom.

Eskom 2000c. Annual Report 2000. Sandton, South Africa: Eskom. 
Howells, M., 1999. Baseline and Greenhouse Gas Mitigation Options for Bulk Energy Supply, South African Country Study on Climate Change, Draft Report, Energy Research Institute, University of Cape Town.

IEA (International Energy Agency), 1998. World Energy Outlook - 1998 Update. Paris: IEA/OECD.

Kartha, S., Lazarus, M., and Bosi, M., 2002. Practical Baseline Recommendations for Greenhouse Gas Mitigation Projects in the Electric Power Sector, OECD and IEA Information Paper. Paris: International Energy Agency.

Kerr, T., Morgan, R., Haydel, J., and Thapa, B., 2002. Average Displaced Emissions Rate (ADER): Approach and Methodology. http://www.epa.gov/ttnchie1/conference/ei11/ poster/morgan.pdf

Langrock, T, Michaelowa, A \& Greiner, S 2000. Defining investment additionality for CDM projects - practical approaches. Hamburg, Hamburgisches Welt-Wirtschafts-Archiv.

Lazarus, M., Kartha, S., and Bernow, S., 2000. Key Issues in Benchmark Baselines for the CDM: Aggregation, Stringency, Cohorts, and Updating. Boston: Tellus Institute. http://www.tellus.org/seib/publications/cdmjune2000.pdf

Liu, D \& P Rogers 2000, Baseline determination for greenhouse gas abatement. In Ghosh, P (Ed) 2000, Implementation of the Kyoto Protocol: Opportunities and pitfalls for developing countries. Manila: Asian Development Bank

Marnay, C., Fisher, D., Murtishaw, S., Phadke, A., Price, L., and Sathaye, J., 2002. Estimating Carbon Dioxide Emissions Factors for the California Electric Power Sector. Berkeley, CA: Lawrence Berkeley National Laboratory (LBNL). LBNL-49945

Meyers, S., 2000. Determining Baselines and Additionality for the Clean Development Mechanism: Are Simplified Methods Viable? (unpublished memo). Berkeley, CA: LBNL.

Meyers, S., Marnay, C., Schumacher, K., and Sathaye J., 2000. Estimating Carbon Emissions Avoided by Electricity Generation and Efficiency Projects: A Standardized Method (MAGPWR). Berkeley, CA: LBNL. LBNL-46063

Milligan, M., Porter, K., Parsons, B., and Caldwell, J., 2002. Wind Energy and Power System Operations: A Survey of Current Research and Regulatory Actions. The Electricity Journal 15(2): 56-67.

NER (National Electricity Regulator), 2000. Electricity Supply Statistics for South Africa 1999. Johannesburg: NER.

NER, 2001. Electricity Supply Statistics for South Africa 2000. Johannesburg: NER. http://www.ner.org.za/publications/ess/2000.pdf

Parkinson, S., Begg, K., Bailey, P., and Jackson, T., 2001. "Accounting for Flexibility Against Uncertain Baselines: Lessons from Case Studies in the Eastern European Energy Sector," Climate Policy 1: 55-73.

Price, L., Michaelis, L., Worrell, E., and Khrushch, M., 1998. "Sectoral Trends and Driving Forces of Global Energy Use and Greenhouse Gas Emissions," Mitigation and Adaptation Strategies for Global Change 3: 263-319. 
Price, L., Worrell, E., and Khrushch, M., 1999. Sector Trends and Driving Forces of Global Energy Use and Greenhouse Gas Emissions: Focus on Industry and Buildings. LBNL-43746. Berkeley, CA: Lawrence Berkeley National Laboratory.

Roggen, Wouter, 2000. Personal communication, Athlone Power Station Manager.

Roy, J. and Das, S., 2001. Potential Multiproject Baselines for Power Sector in the Eastern Region of India.

SANEA (South African National Energy Association), 1998. South Africa Energy Profile. Sandton, South Africa: SANEA.

Sathaye, J., Price, L., Worrell, E., Ruth, M., Schaeffer, R., Macedo Costa, M., Yanjia, W., Roy, J., Das, S., Winkler, H., Spalding-Fecher, R., Afrane-Okese, Y., and Davidson, O., 2001. Multi-Project Baselines for Evaluation of Industrial Energy Efficiency and Electric Power Projects. LBNL-48242. Berkeley, CA: Lawrence Berkeley National Laboratory.

Shrestha, R \& Timilsina, G R 2002. The additionality criterion for identifying clean development mechanism projects under the Kyoto Protocol. Energy Policy 30 (1): 73-79.

Spalding-Fecher, R., 2002. A final analysis of a potential CDM project in S. Africa: Darling wind farm. Cape Town: Energy and Development Research Centre, University of Cape Town.

Spalding-Fecher, R., Clark A., Davis M., and Simmonds G., 2002. The economics of energy efficiency for the poor - a South African case study. Energy: The International Journal 27 (12): 1099-1117.

Spalding-Fecher, R 2002. Financial and economic analysis of CDM projects. O Davidson and D Sparks (Eds). Developing energy solutions for climate change: South African research at EDRC, Energy \& Development Research Centre, University of Cape Town: 83-103.

U.S. Energy Information Administration, 1999. India: Environmental Issues. November. http://www.eia.doe.gov/emeu/cabs/indiaenv.html

Winkler, H., Spalding-Fecher, R., Sathaye J., and Price L., 2001. Multiproject Baselines for Potential Clean Development Mechanism Projects in the Electricity Sector in South Africa. J. of Energy in Southern Africa, 12 (4): 449-457.

World Bank Prototype Carbon Fund, 2000. Learning from the Implementation of the Prototype Carbon Fund. Washington, DC: World Bank.

Ybema, J. R., Cloin, J., Nieuwenhout, F. D. J., Hunt, A. C. \& Kaufman, S. L., 2000. Towards a streamlined CDM process for Solar Home Systems: Case studies in selected countries. Petten, Netherlands, ECN 